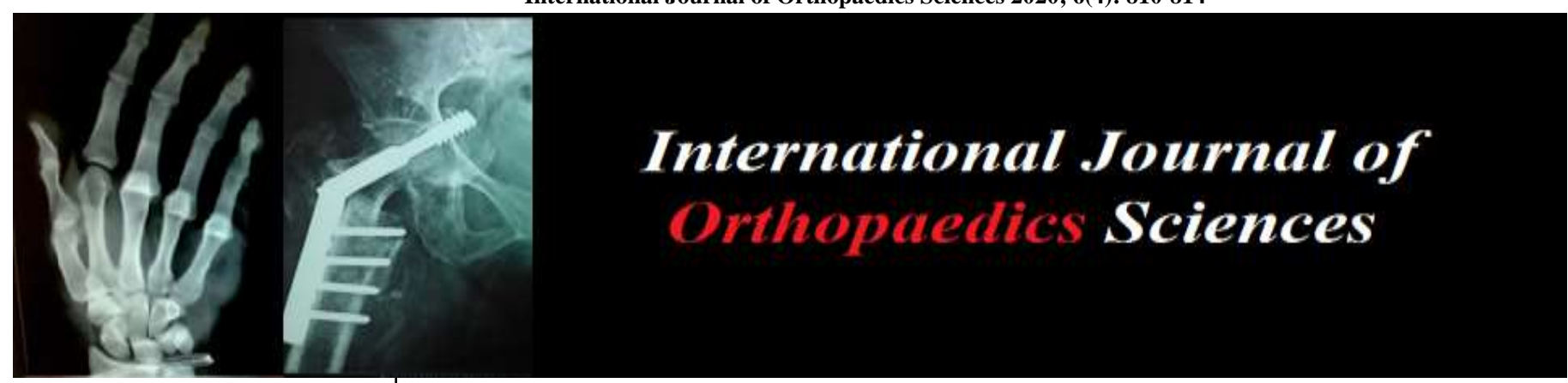

E-ISSN: 2395-1958

P-ISSN: 2706-6630

IJOS 2020; 6(4): 810-814

(C) 2020 IJOS

www.orthopaper.com

Received: 03-09-2020

Accepted: 15-10-2020

Bikramjit Gayen

RKMSP, 99 Sarat Bose Road,

Kolkata, West Bengal, India

Dipak Kumar Jha

RKMSP, 99 Sarat Bose Road,

Kolkata, West Bengal, India

Prasanta Kumar Pujari

RKMSP, 99 Sarat Bose Road,

Kolkata, West Bengal, India

Atanu Chartterjee

RKMSP, 99 Sarat Bose Road,

Kolkata, West Bengal, India

Syamsundar Mondal

RKMSP, 99 Sarat Bose Road,

Kolkata, West Bengal, India

Corresponding Author:

Bikramjit Gayen

RKMSP, 99 Sarat Bose Road,

Kolkata, West Bengal, India

\section{Outcome of platelet rich plasma injection in osteoarthritis knee}

\author{
Bikramjit Gayen, Dipak Kumar Jha, Prasanta Kumar Pujari Atanu \\ Chartterjee and Syamsundar Mondal
}

DOI: https://doi.org/10.22271/ortho.2020.v6.i41.2423

\section{Abstract}

Background: Osteoarthritis (OA) knee is one of the most prevalent musculoskeletal disorders in elderly population. It has got various treatment options but most are unsatisfactory. PRR (Platelet rich plasma) injection is a relatively new procedure. Following injection activated platelets secrete growth factors (platelet derived growth factor, epidermal growth factor). These growth factors reduce inflammation, cartilage degradation and promote chondrocyte proliferation.

Aim and Objectives: To compare the efficacies of treatment with PRP injection and conservative treatment with NSAIDS and exercise in OA knee.

Materials and Methods: This was a observational study in which comparisons of different outcomes were made on the efficacies of the treatments with PRP injection and compared to conservative treatment with NSAIDS and exercise in OA knee. The study was conducted in the Department of Orthopaedics in Ramkrishna Mission Seva Pratishthan. A total number of 60 patients with power $80 \%$ were randomly selected from the patients with OA attended OPD during the period from September 2017 to September 2019. The patients were divided into two groups of 30 patients in each group. The patients of the one group were treated with intra-articular PRP injection and the patients of another group were treated conservatively with NSAIDS and exercise. After the completion of treatments the patients were followed-up for 6 months and the outcomes of the treatments were assessed by WOMAC (The Western Ontario and McMaster Universities Osteoarthritis Index) knee assessment scoring system.

Results: At 6 month the completion of treatments it was found that both clinical and functional improvements of the patients were significantly better than the initiation of treatments $(p<0.0001)$. However, the improvements of the patients treated with PRP injection were significantly better than the patients treated conservatively with NSAIDS and exercise $(p<0.001)$.

Conclusion: From the results of the study it may be concluded that PRP injection is better than conservative treatment with NSAIDS and exercise to treat OA knee.

Keywords: Osteoarthritis, platelet rich plasma, knee, NSAID, WOMAC

\section{Introduction}

\subsection{Background}

Osteoarthritis (OA) is one of the most prevalent musculoskeletal diseases in the world [1]. Kellgren and Lawrence radiologically classified OA knee into four grades as (Grade I-IV) ${ }^{[2]}$. A number of treatments were found to be less effective in reducing pain, improvement over functional activities and in reducing disease progression. A relatively new procedure of treatment of $\mathrm{OA}$ is the use of cell elements and bio mediators. In this context, Platelet Rich Plasma (PRP) has been configured as a prospective in improving clinical and structural outcome by delivering a high concentration of growth factors that mediate cartilage healing and remodelling. The potentiality has been shown in vivo and in vitro studies; however, its real efficacy in OA is not well established ${ }^{[3]}$.

When PRP is injected into the injured site, platelets are activated by endogenous thrombin and/or intra-articular collagen ${ }^{[4]}$. Once activated, there is secretion of growth factors by degranulation of the $\alpha$-granules ${ }^{[5]}$. Among secreted sub-stances we can find: platelet-derived growth factor (PDGF), interleukin-1 receptor antagonist (IL-1RA), soluble receptor of tumour necrosis factor $\alpha$ (TNF-RI), transforming growth factor $\beta$ (TGF- $\beta$ ), platelet factor 4 (PF4), vascular endothelial growth factor (VEGF), epidermal growth factor (EGF), insulin-like 
growth factor (IGF), osteocalcin (Oc), osteonectin (On), fibrinogen, vitronectin, fibronectin and thrombospondin-1 (TSP-1) ${ }^{[6]}$

Many of these mediators act as anti-catabolic and antiinflammatory agents. The antagonist of IL-1 receptor inhibits activation of $\mathrm{NF} \mathrm{KB}$ gene, cytokine involved in apoptosis and inflammation process ${ }^{[3,6]}$. Moreover, the soluble receptors of the tumour necrosis factor bind to TNF- $\alpha$ preventing its interaction with cellular receptors and its pro-inflammatory signalling. TGF- $\beta 1$ also acts as a factor inhibiting cartilage degradation, regulating and enhancing gene expression of tissue inhibitors of metalloproteinase (TIMP-1). ${ }^{7}$ Other factors such as IGF-1, PDGF and TGF- $\beta 1$ favour the stabilization of cartilage by controlling the metabolic functions of chondrocytes and subchondral bone, maintaining the homeostasis between the synthesis and degradation of proteoglycans, and stimulating the proliferation of chondrocytes ${ }^{[8,9]}$. It was also found that platelet growth factors stimulate synovial fibroblasts to synthesize hyaluronic acid $^{[8]}$.

Thus in this study an attempt was made to compare the efficacy of PRP over conservative treatment with NSAIDS to treat the patients with OA.

\subsection{Objectives}

1. To assess clinical, functional and radiological effectiveness of PRP injection in early osteoarthritis knee compared with conservative treatment with exercise and NSAIDS (Non-Steroidal Anti-Inflammatory Drugs).

2. To assess adverse reaction of PRP injection in knee osteoarthritis, if any.

\section{Methods}

\subsection{Type of Study}

This was a hospital based comparative observational study.

\subsection{Study Settings}

The study was conducted at Department of Orthopaedics, Ramkrishna Mission Seva Pratishthan (RKMSP), Kolkata, West Bengal during the period from September 2017 to September 2019.

\subsection{Inclusion Criteria}

A. Patients with early grade of OA knee (Grade- I-III).

B. Patients without previous treatment with PRP or NSAID

C. Patients without pregnancy

D. Patients with written consent to be included in the study

\subsection{Exclusion Criteria}

1. Patients with advanced grade of OA knee (Grade-IV).

2. Patients with previous treatment with PRP or NSAID

3. Patients with pregnancy

4. Patients without written consent to be included in the study

\subsection{Sample Size}

Formula for computing sample size to compare two groups: Mean of group 1= M1

Mean of group 2= M2

Common standard deviation $(\mathrm{SD})=\sigma$
Effect Size $=$ Difference per SD $($ DSD $)=($ M1-M2 $) / \sigma$

(Absolute difference of M1 and M2 is used for calculation)

As per the study by Raeissadat et al. ${ }^{[10]}$ The mean WOMAC index after treatment with PRP in one group of patients and with hyaluronic acid (HA) in other group patients with Knee osteoarthritis were $39.50 \pm 17.06(n=77)$ and $28.69 \pm 16.69$ $(\mathrm{n}=63)$ respectively.

Here $\mathrm{M} 1=39.50, \mathrm{M} 2=28.69$, Common $\mathrm{SD}=16.89$. Thus the effect size $=0.64$. From the Cohen Power Tables for effect size it had been found that there was a need of 30 patients in each group. The number of patients in each group was in the ratio 1:1. Thus the sample size for the study was 60 with power $80 \%$.

\subsection{Sampling Techniques}

The patients were selected randomly and were assigned into two groups randomly. The random numbers was used from Kevin Conroy: 5120 Random Numbers $(<5 \mathrm{k}, 2002)$ [Call the JavaScript pseudo-random number generator.] Website: RandomNumber.org, 2004.

\subsection{Materials and Methods}

Ethical approval was obtained from Institutional Ethics Committee (IEC), RKMSP before the initiation of study. 60 patients with OA who were attended OPD during the period were selected randomly as per the inclusion and exclusion criteria and were allocated into two groups randomly with the help of random numbers. The patients of one group were treated with single dose PRP injections in both knees and patients of other group were treated with NSAIDS and regular quadriceps exercise.

PRP was prepared from patient's own blood by centrifugation and 20ml PRP was injected in each knee within 2 hours of preparation in sterile conditions. Platelet concentration in PRP was $1248000 / \mathrm{cmm}$.

All the patients were followed up at 4 weeks interval up to 6 months. All the patients of the two groups were compliant to follow-up.

In each follow up patients were assessed according to WOMAC (The Western Ontario and McMaster Universities Osteoarthritis Index) knee assessment scoring system.

\section{Statistical analysis}

Statistical Analysis was performed with help of Epi Info (TM) 7.2.2.2 EPI INFO is a trademark of the Centers for Disease Control and Prevention (CDC). Descriptive statistical analysis was performed to calculate the means with corresponding standard deviations (s.d.). Chi-square $\left(x^{2}\right)$ test was performed to find the associations. Independent samples t-test was used to compare the means of the two groups. $p<0.05$ was taken to be statistically significant.

\section{Results}

Out of 60 patients under study 30(50.0\%) of the patients were treated with single dose Platelet Rich Plasma (PRP) injection (PRP Group) and rest 30(50.0\%) of the patients were treated with NSAIDS and exercise (Non-PRP Group). Thus the patients of the two groups were in the ratio $1: 1$.

Table 1: Comparison of base parameters of the patients of the two groups

\begin{tabular}{|c|c|c|c|c|}
\hline Parameters & PRP $(\mathbf{n}=30)$ & Non-PRP $(\mathbf{n}=30)$ & Test tatistic & p-value \\
\hline Age (in years); mean \pm s.d. & $49.33 \pm 7.59$ & $50.83 \pm 6.41$ & $\mathrm{t}_{58}=\quad 0.82$ & 0.41 \\
\hline Gender (Male: Female) & $13(43.3 \%): 17(56.7 \%)$ & $9(30.0 \%): 21(70.0 \%)$ & $\chi^{2}=1.14$ & 0.28 \\
\hline Grade of osteoarthritis (II: III) & $6(20.0 \%): 24(80.0 \%)$ & $5(16.7 \%): 25(83.3 \%)$ & $\chi^{2}=0.11$ & 0.73 \\
\hline
\end{tabular}


t-test showed that there was no significant difference in mean age of the patients of the two groups $\left(\mathrm{t}_{58}=0.82 ; \mathrm{p}=0.41\right)$. Thus the patients of the two groups were matched for their ages. Chi-square $\left(x^{2}\right)$ test showed that there was no significant association between gender and the patients of the two groups $(p=0.28)$. Thus the patients of the two groups were matched for their gender.

Also no significant difference was found between grade of osteoarthritis and the patients of the two groups. Thus the patients of the two groups were comparable for their grade of osteoarthritis.

Table 2: Comparison of pre-treatment and post-treatment at 6 month WOMAC (Western Ontario McMasters Universities Osteoarthritis Index) score of the patients of the two groups

\begin{tabular}{|c|c|c|c|c|}
\hline WOMAC Index & PRP $(n=30)$ & Non-PRP $(n=30)$ & t-test $\left(t_{58}\right)$ & p-value \\
\hline \multicolumn{5}{|c|}{ Pre- treatment } \\
\hline Mean \pm s.d. & $47.32 \pm 17.12$ & $32.11 \pm 21.18$ & \multirow{3}{*}{3.06} & \multirow{3}{*}{0.003} \\
\hline Median & 45.83 & 26.56 & & \\
\hline Range & $10.41-85.41$ & $8.33-91.60$ & & \\
\hline \multicolumn{5}{|c|}{ Post- treatment at 6 month } \\
\hline Mean \pm s.d. & $10.97 \pm 9.91$ & $36.49 \pm 16.89$ & \multirow{3}{*}{7.13} & \multirow{3}{*}{$<0.0001$} \\
\hline Median & 10.41 & 34.37 & & \\
\hline Range & $0-37.50$ & $11.45-80.20$ & & \\
\hline t-test $\left(\mathrm{t}_{58}\right)$ & 10.06 & 0.88 & & \\
\hline p-value & $<0.0001 \mathrm{~S}$ & $0.37 \mathrm{NS}$ & & \\
\hline \multicolumn{5}{|c|}{ Difference of Pre- treatment and Post- treatment of WOMAC Index } \\
\hline Mean \pm s.d. & $36.35 \pm 14.48$ & $-4.38 \pm 15.23$ & \multirow{3}{*}{10.61} & \multirow{3}{*}{$<0.0001$} \\
\hline Median & 34.38 & -3.13 & & \\
\hline Range & $10.41-72.92$ & $-33.33-22.92$ & & \\
\hline
\end{tabular}

S-Statistically significant

NS-Statistically not significant

t-test showed that the pre-treatment mean WOMAC Index of the patients with NSAID and exercise of Group-B was significantly lower than that of the patients with PRP $(\mathrm{p}=0.003)$. t-test showed that the mean WOMAC Index after treatment of the patients with PRP was significantly lower than that of the patients with NSAID and exercise $(p<0.0001)$.

Also in PRP group the mean WOMAC Index after treatment of the patients was significantly lower than that of pretreatment $(p<0.0001)$. However, in non-PRP group the mean
WOMAC Index after treatment of the patients was higher than that of pre-treatment but it was not significant $(\mathrm{p}=0.37)$. Thus in conclusion PRP was found to be more effective than NSAID with exercise. Also the base line WOMAC Index of the patients with NSAID with exercise was lower than that of the patients with PRP. Thus the improvement of WOMAC Index of the patients with PRP was much higher than the patients with NSAID with exercise. None of the patients treated with PRP had developed any adverse affect.

Table 3: Comparison of different parameters before treatment at different time intervals of the patients of the two groups.

\begin{tabular}{|c|c|c|c|c|}
\hline Parameters related to WOMAC Index & PRP $(\mathbf{n}=\mathbf{3 0})$ & Non-PRP $(\mathbf{n}=\mathbf{3 0})$ & t-test(ts8) & p-value \\
\hline Pain1 & $2.60 \pm 1.07$ & $2.03 \pm 1.30$ & 1.844 & $0.07 \mathrm{NS}$ \\
\hline Pain 2 & $2.83 \pm 1.26$ & $2.20 \pm 1.21$ & 1.981 & $0.052 \mathrm{NS}$ \\
\hline Pain 3 & $1.33 \pm 1.32$ & $1.03 \pm 1.10$ & 0.956 & $0.343 \mathrm{NS}$ \\
\hline Pain 4 & $1.07 \pm 1.20$ & $0.57 \pm 0.94$ & 1.799 & $0.078 \mathrm{NS}$ \\
\hline Pain 5 & $2.07 \pm 1.36$ & $1.57 \pm 1.48$ & 1.362 & $0.178 \mathrm{NS}$ \\
\hline Stiffness1 & $2.23 \pm 1.63$ & $1.33 \pm 1.21$ & 2.423 & $0.019 \mathrm{~S}$ \\
\hline Stiffness 2 & $1.47 \pm 1.20$ & $0.57 \pm 0.97$ & 3.200 & $0.002 \mathrm{~S}$ \\
\hline Functional1 & $2.53 \pm 1.20$ & $2.07 \pm 1.44$ & 1.367 & $0.177 \mathrm{NS}$ \\
\hline Functional 2 & $2.70 \pm 1.24$ & $2.13 \pm 1.38$ & 1.673 & $0.100 \mathrm{~S}$ \\
\hline Functional 3 & $2.50 \pm 1.14$ & $1.67 \pm 1.21$ & 2.745 & $0.008 \mathrm{~S}$ \\
\hline Functional 4 & $2.33 \pm 1.12$ & $1.37 \pm 1.13$ & 3.323 & $0.002 \mathrm{~S}$ \\
\hline Functional 5 & $3.30 \pm 0.95$ & $3.17 \pm 1.18$ & 0.482 & $0.631 \mathrm{NS}$ \\
\hline Functional 6 & $1.10 \pm 0.92$ & $0.80 \pm 1.10$ & 1.147 & $0.256 \mathrm{NS}$ \\
\hline Functional 7 & $2.23 \pm 1.01$ & $1.50 \pm 1.25$ & 2.500 & $0.015 \mathrm{~S}$ \\
\hline Functional 8 & $1.60 \pm 1.19$ & $1.33 \pm 1.24$ & 0.849 & $0.399 \mathrm{NS}$ \\
\hline Functional 9 & $0.87 \pm 1.01$ & $0.70 \pm 1.21$ & 0.580 & $0.564 \mathrm{NS}$ \\
\hline Functional 10 & $0.70 \pm 0.88$ & $0.40 \pm 0.86$ & 1.342 & $0.185 \mathrm{NS}$ \\
\hline Functional 11 & $0.80 \pm 0.89$ & $0.67 \pm 1.12$ & 0.510 & $0.612 \mathrm{NS}$ \\
\hline Functional 12 & $1.90 \pm 1.18$ & $0.87 \pm 1.25$ & 3.283 & $0.002 \mathrm{~S}$ \\
\hline Functional 13 & $1.60 \pm 1.35$ & $0.37 \pm 0.93$ & 4.115 & $<0.001 \mathrm{~S}$ \\
\hline Functional 14 & $1.73 \pm 1.11$ & $0.27 \pm 0.69$ & 6.134 & $<0.001 \mathrm{~S}$ \\
\hline Functional 15 & $3.10 \pm 1.06$ & $2.00 \pm 1.49$ & 3.299 & $0.002 \mathrm{~S}$ \\
\hline Functional 16 & $2.80 \pm 1.35$ & $1.70 \pm 1.29$ & 3.227 & $0.002 \mathrm{~S}$ \\
\hline Functional 17 & $1.13 \pm 0.90$ & $0.43 \pm 0.86$ & 3.084 & $0.003 \mathrm{~S}$ \\
\hline
\end{tabular}


Table 4: Comparison of different parameters after treatment at different time intervals of the patients of the two groups.

\begin{tabular}{|c|c|c|c|c|}
\hline Parameters related to WOMAC Index & PRP $(\mathbf{n}=\mathbf{3 0})$ & Non-PRP $(\mathbf{n}=\mathbf{3 0})$ & t-test $\left(\mathbf{t}_{\mathbf{5} 8}\right)$ & $\mathbf{p}$-value \\
\hline Pain1 & $0.57 \pm 0.82$ & $2.00 \pm 1.20$ & 5.397 & $<0.001 \mathrm{~S}$ \\
\hline Pain 2 & $0.97 \pm 1.07$ & $2.47 \pm 1.04$ & 5.512 & $<0.001 \mathrm{~S}$ \\
\hline Pain 3 & $0.10 \pm 0.40$ & $1.23 \pm 1.22$ & 4.822 & $<0.001 \mathrm{~S}$ \\
\hline Pain 4 & $0.03 \pm 0.18$ & $0.70 \pm 1.02$ & 3.517 & $<0.001 \mathrm{~S}$ \\
\hline Pain 5 & $0.53 \pm 0.97$ & $1.77 \pm 1.30$ & 4.150 & $<0.001 \mathrm{~S}$ \\
\hline Stiffness1 & $0.37 \pm 0.72$ & $1.57 \pm 1.14$ & 4.893 & $<0.001 \mathrm{~S}$ \\
\hline Stiffness 2 & $0.27 \pm 0.45$ & $0.93 \pm 1.28$ & 2.683 & $0.011 \mathrm{~S}$ \\
\hline Functional1 & $0.97 \pm 1.07$ & $2.53 \pm 1.11$ & 5.586 & $<0.001 \mathrm{~S}$ \\
\hline Functional 2 & $1.03 \pm 1.10$ & $2.60 \pm 1.13$ & 5.440 & $<0.001 \mathrm{~S}$ \\
\hline Functional 3 & $0.70 \pm 0.79$ & $1.83 \pm 1.23$ & 4.230 & $<0.001 \mathrm{~S}$ \\
\hline Functional 4 & $0.50 \pm 0.68$ & $1.57 \pm 1.10$ & 4.501 & $<0.001 \mathrm{~S}$ \\
\hline Functional 5 & $1.83 \pm 1.62$ & $3.17 \pm 1.23$ & 3.585 & $<0.001 \mathrm{~S}$ \\
\hline Functional 6 & $0.30 \pm 0.53$ & $1.07 \pm 1.01$ & 3.660 & $<0.001 \mathrm{~S}$ \\
\hline Functional 7 & $0.77 \pm 0.90$ & $1.97 \pm 0.93$ & 5.091 & $<0.001 \mathrm{~S}$ \\
\hline Functional 8 & $0.37 \pm 0.67$ & $1.60 \pm 1.10$ & 5.242 & $<0.001 \mathrm{~S}$ \\
\hline Functional 9 & $0.27 \pm 0.52$ & $0.77 \pm 1.22$ & 2.060 & $0.046 \mathrm{~S}$ \\
\hline Functional 10 & $0.03 \pm 0.18$ & $0.50 \pm 0.94$ & 2.676 & $0.012 \mathrm{~S}$ \\
\hline Functional 11 & $0.17 \pm 0.53$ & $0.70 \pm 1.06$ & 2.473 & $0.017 \mathrm{~S}$ \\
\hline Functional 12 & $0.50 \pm 0.73$ & $1.70 \pm 1.93$ & 3.181 & $0.003 \mathrm{~S}$ \\
\hline Functional 13 & $0.07 \pm 0.25$ & $0.47 \pm 0.94$ & 2.257 & $0.031 \mathrm{~S}$ \\
\hline Functional 14 & $0.10 \pm 0.31$ & $0.37 \pm 0.76$ & 1.774 & $0.084 \mathrm{NS}$ \\
\hline Functional 15 & $0.50 \pm 0.78$ & $2.33 \pm 1.49$ & 5.966 & $<0.001 \mathrm{~S}$ \\
\hline Functional 16 & $0.67 \pm 0.76$ & $2.17 \pm 1.37$ & 5.257 & $<0.001 \mathrm{~S}$ \\
\hline Functional 17 & $0.10 \pm 0.31$ & $0.63 \pm 1.10$ & 2.563 & $0.015 \mathrm{~S}$ \\
\hline
\end{tabular}

\section{Discussion}

The action of the PRP began to be studied in osteoarthritis in order to increase the anabolic activity of chondrocytes. The platelet-rich plasma is capable of inducing proliferation of mesenchymal cells, as demonstrated in vitro by Huang et al. [11]. and Kilian et al. ${ }^{[12]}$ PRP can regulate the action of metalloproteinase and activate mechanisms of matrix regenerators such as the synthesis of collagen and proteoglycans ${ }^{[13]}$. Nakagawa et al. ${ }^{[14]}$ demonstrated the in vitro efficacy of PRP stimulating chondrocyte proliferation and synthesis of collagen. Mishra et al. ${ }^{15}$ showed that the platelet-rich plasma could lead to proliferation of fibroblasts in vitro, as well as stimulate the expression of genes responsible for the chondrogenic and osteogenic differentiation.

Kon et al. ${ }^{[16]}$ conducted a prospective study in 2010 in which 100 patients with knee osteoarthritis were treated with PRP and evaluated at six and twelve months through IKD Cand EQ-VAS scales. There was a favourable response in the first six months, not sustained after twelve months, despite remaining significantly above the initial scores.

Sampson et al. ${ }^{[17]}$ in 2010 evaluated the use of PRP in knee $\mathrm{OA}$ in 14 patients using the KOOS and Brittberg-Peterson VAS scores, and followed them for 52 weeks. There was a significant clinical improvement in patients treated with PRP. Sánchez et al. ${ }^{[18]}$ in 2012, in a double-blind, randomized trial, compared the PRP and hyaluronic acid in 176 patients with knee OA. The scores used for the analysis were WOMAC (Western Ontario McMasters Universities Osteoarthritis Index) and Lequesne. Treatment with PRP reduced by $50 \%$ the WOMAC index (primary outcome) and showed a trend of improvement in secondary outcomes, however with no statistical significance.

Vaquerizo et al. ${ }^{[19]}$ published in 2013 a study with similar design to the study by Sanchez, where 96 patients were evaluated for 48 weeks. The PRP showed better responses in all parameters analyzed, both in 24 and in 48 weeks, including the percentage of responders of OMERACT-OARSI (Outcome Measures for Rheumatology Committee and Osteoarthritis Research Society International Standing
Committee for Clinical Trials Response Criteria Initiative.

Another study published in 2013 conducted by Say et al. ${ }^{\text {[20] }}$ compared a single PRP injection with three hyaluronic acid (HA) injections in individuals with knee osteoarthritis. Clinical evaluation was made by KOOS (Knee injury and Osteoarthritis Outcome Score) and VAS (Visual Analog Scale) scores. The study showed clinical improvement with both treatments after three and six months of the procedures, however, with a better response in patients treated with PRP. In this study, the participants reflect the general population of Kolkata. There were no statistically significant differences in age, gender and radiological grading of osteoarthritis of the participants. From this study, we found that there was significant improvement of pain, stiffness and physical function in patients treated with PRP injection. There was no significant improvement of pain, stiffness and physical function in patients treated with NSAIDS and exercise. PRP injection is found to be clinically in functionally very effective in OA knee (Grade I-III) up to 6 month follow-up. In 14 patients we have followed-up up to 12 months. Before PRP injection the mean WOMAC score was 0.488, after 12 month follow up the mean score was 0.13. After 1 year of PRP injection also, clinical and functional improvement was very good. But there was no radiological improvement of OA grading following PRP injection. There was no adverse reaction to PRP injection. Patients were able to do their daily activities on the day of injection. From this study, it can be concluded that PRP injection is an effective treatment option in osteoarthritis knee (Grade I-III) and results are promising even after 1 year of injection.

\section{Acknowledgments}

We would like to thank blood bank and operation theatre staff of RKMSP for their support in this study. Also we would like to convey our sincere thanks to Dr. Syamsundar Mandal, Ph. D. Head, Department of Epidemiology \& Biostatistics, Chittaranjan National Cancer Institute, Kolkata for his valuable guidance for the design of study and in the analysis of data. 


\section{References}

1. Gerwin N, Hops C, Lucke A. Intraarticular drug delivery in osteoarthritis. Adv Drug Deliv Rev 2006;58:226-42.2.

2. Kellgren JH, Lawrence JS: Radiological assessment of osteoarthrosis. Ann Rheum Dis 1957;16:494-502.

3. Pourcho AM, Smith J, Wisniewski SJ, Sellon JL. Intraarticular platelet-rich plasma injection in the treatment of knee osteoarthritis: review and recommendations. Am J Phys Med Rehabil 2014;93:S108-21.

4. Harrison S, Vavken P, Kevy S, Jacobson M, Zurakowski D, Murray MM. Platelet activation by collagen provides sustained release of anabolic cytokines. Am J Sports Med 2011;39(4):729-34.

5. Ahmad Z, Howard D, Brooks RA, Wardale J, Henson F, GetgoodA, et al. The role of platelet-rich plasma in musculoskeletal science. J R Soc Med Short Rep 2012;3:40.

6. Lacci KM, Dardik A. Platelet-rich plasma: support for its use in wound healing. Yale J Biol Med 2010;83:1-9.

7. Van Buul GM, Koevoet WLM, Kops N, Bos PK, Verhaar JAN, Weinans $\mathrm{H}$ et al. Platelet-rich plasma releasate inhibits inflammatory processes in osteoarthritic chondrocytes. Am J Sports Med 2011;39:2362-70.

8. Mix KS, Sporn MB, Brinckerhoff CE, Eyre D, Schurman DJ. Novel inhibitors of matrix metalloproteinase gene expressions potential therapies for arthritis. Clin Orthop Relat Res 2004;427:129-37.

9. Anitua E, Sánchez M, Nurden AT, Zalduendo MM, de la Fuente M, Azofra J, et al. Platelet-released growth factors enhance the secretion of hyaluronic acid and induce hepatocyte growth factor production by synovial fibroblasts from arthritic patients. Rheumatology 2007;46:1769-72.

10. Raeissadat et al. Knee Osteoarthritis Injection Choices: Hyaluronic Acid Versus Platelet Rich Plasma. Clinical Medicine Insights: Arthritis and Musculoskeletal Disorders 2015:8:18. doi: 10.4137/CMAMD.S17894.

11. Huang Q, Wang YD, Wu T, Jiang S, Hu YL, Pei GX. Preliminary separation of the growth factors in plateletrich plasma: effects on the proliferation of human marrow-derived mesenchymal stem cells. Chin Med J (Engl) 2009;122(1):83-7.

12. Kilian O, Flesch I, Wenisch S, Taborski B, Jork A, Schnettler R,et al. Effects of platelet growth factors on human mesenchymal stem cells and human endothelial cells in vitro.Eur J Med Res 2004;9(7):337-44.

13. Frazer A, Bunning RA, Thavarajah M, Seid JM, Russell RG.Studies on type II collagen and aggrecan production inhuman articular chondrocytes in vitro and effects of transforming growth factor-beta and interleukin1beta.Osteoarthr Cartil 1994;2:235-45.

14. Nakagawa K, Sasho T, Arai M, Kitahara S, Ogino S, Wada Y. Effects of autologous platelet-rich plasma on the metabolism of human articular chondrocytes. Osteoarthr Cartil 2007;15(2):134.

15. Mishra A, Tummala P, King A, Lee B, Kraus M, Tse V et al. Buffered platelet-rich plasma enhances mesenchymal stemcell proliferation and chondrogenic differentiation. TissueEng Part C Methods 2009;15:4315.

16. Kon E, Filardo G, Buda E, Timoncini A, Di Martino A, Cenacchi A et al. Platelet-rich plasma: intra-articular knee injections produced favourable results on degenerative cartilage lesions. Knee Surg Sports
Traumatol Arthrosc 2010;18:472-9.

17. Sampson S, Reed M, Silvers H, Meng M, Mandelbaum B. Injection of platelet-rich plasma in patients with primary and secondary knee osteoarthritis: a pilot study. Am J Phys Med Rehabil 2010;89(12):961-9.

18. Sánchez M, Fiz N, Azofra J, Usabiaga J, Recalde EA, Gutierrez AG et al. A randomized clinical trial evaluating plasma rich in growth factors (PRGF-endoret) versus hyaluronic acid in the short-term treatment of symptomatic knee osteoarthritis. Arthroscopy 2012;28(8):1070-8.

19. Vaquerizo V, Plasencia MA, Arribas I, Seijas R, Padilla $\mathrm{S}$, OriveG, et al. Comparison of intra-articular injections of plasma rich in growth factors (PRGF-endoret) versus durolanehyaluronic acid in the treatment of patients with symptomatic osteoarthritis: a randomized controlled trial. Arthroscopy 2013;29(10):1635-43.

20. Say F, Gürler D, Yener K, Bülbül M, Malkoc, M. Platelet-rich plasma injection is more effective than hyaluronic acid in the treatment of knee osteoarthritis. Acta Chir Orthop Traumatol Cech 2013;80(4):278-83. 